First Peoples Child \& Family Review

An Interdisciplinary Journal Honouring the Voices, Perspectives, and Knowledges of First Peoples through Research, Critical Analyses, Stories, Standpoints and Media Reviews

\title{
"Make Them Stop it": What Aboriginal Children and Youth in Australia Are Saying About Bullying
}

\section{Juli Coffin}

\section{Volume 6, Number 1, 2011}

URI: https://id.erudit.org/iderudit/1068898ar

DOI: https://doi.org/10.7202/1068898ar

See table of contents

Publisher(s)

First Nations Child and Family Caring Society of Canada

ISSN

1708-489X (print)

2293-6610 (digital)

Explore this journal

Cite this article

Coffin, J. (2011). "Make Them Stop it": What Aboriginal Children and Youth in Australia Are Saying About Bullying. First Peoples Child \& Family Review, 6(1), 83-98. https://doi.org/10.7202/1068898ar

\section{Article abstract}

This paper explores and summarizes a three year research program into contextualizing bullying in an Aboriginal cultural environment for youth and children. Bullying is not a new concept; it has been passed down from one generation to the next for many years. Effects of bullying can be long term and often manifest as being the causal pathway to other undesirable behaviours. Among children and youth effects of bullying are seen in many forms, for Aboriginal children and youth these effects are magnified. Aboriginal children and youth are already over represented in truancy, juvenile detention and anti social behaviours, bullying is in the mix and it is preventable. Intra racial bullying and turning inward on one's own cultural group is surely a cry for help with these complex and intricate relationship issues. This paper concludes by considering some of the implications of these findings for future research and conceptualization and has practical solutions for those who are in the care and position to influence the outcomes for Aboriginal communities.
This document is protected by copyright law. Use of the services of Érudit (including reproduction) is subject to its terms and conditions, which can be viewed online.

https://apropos.erudit.org/en/users/policy-on-use/ 


\section{First Peoples Child \& Family Review}

An Interdisciplinary Journal Honoring the Voices, Perspectives and Knowledges of First Peoples through Research, Critical Analyses, Stories, Standpoints and Media Reviews

Volume 6, Number 1, 2011, pp. 83-98

\section{"Make Them Stop it": What Aboriginal Children and Youth in Australia Are Saying About Bullying}

Juli Coffin

a Associate Professor, Aboriginal Health, Combined Universities Centre for Rural Health, Geraldton, Western Australia, Australia, julicoff@cucrh. uwa.edu.au, (08)99560200 te

\section{Introduction}

Bullying among school-aged children and adolescents is a significant problem, in Australia (Rigby 1997; Zubrick SR, Silburn SR et al. 2005; Griffin Smith and Gross 2006) and worldwide (Olweus 1997; Salmivalli, Kaukiainen et al. 2005). Characteristically, bullying can be defined as the repeated infliction of physical, mental or emotional trauma, on one person by another or others. There is a plethora of research on bullying from a mainstream perspective. However, little has been done to explore bullying amongst Aboriginal children and adolescents. The Western Australian Aboriginal Child Health Survey found that approximately one third of Aboriginal school students aged 12 to 17 years had been bullied

Questions or correspondence concerning this article may be addressed to:

Juli Coffin

Phone: (08)99560200

Email: julicoff@cucrh.uwa.edu.au,

\section{Abstract}

This paper explores and summarizes a three year research program into contextualizing bullying in an Aboriginal cultural environment for youth and children. Bullying is not a new concept; it has been passed down from one generation to the next for many years. Effects of bullying can be long term and often manifest as being the causal pathway to other undesirable behaviours. Among children and youth effects of bullying are seen in many forms, for Aboriginal children and youth these effects are magnified. Aboriginal children and youth are already over represented in truancy, juvenile detention and anti social behaviours, bullying is in the mix and it is preventable. Intra racial bullying and turning inward on one's own cultural group is surely a cry for help with these complex and intricate relationship issues. This paper concludes by considering some of the implications of these findings for future research and conceptualization and has practical solutions for those who are in the care and position to influence the outcomes for Aboriginal communities.

Keywords: Aboriginal children; Australia; bullying; social behaviours.

at school, one quarter had been 'picked on'1, and one in five had been subjected to incidents of racism in the six months prior to the survey (Zubrick, Silburn et al. 2005).

Bullying can lead to significant mental and emotional health problems and behavioral difficulties, which is of concern, especially among Aboriginal children and youth who have a much higher risk of developing these clinically significant problems than the general population (Zubrick SR, Silburn SR et al. 2005), than nonAboriginal children (24\% and $17 \%$ respectively). Bullying is also associated with disengagement

1 'Picked on' is similar to being victimized, or ostracized 
from school, an increased likelihood of other aggressive behavior and cyclic behaviors. Aboriginal children have high rates of school truancy (Mellor and Corrigan 2004; Boon 2008), phone help line usage (Kids Help Line 2005), and juvenile detention (Australian Bureau of Statistics 2001; AlHW 2003; Australian Bureau of Statistics 2006). However, no research has investigated whether bullying could be one of the underlying causes of these outcomes. What is becoming evident is that some behavioral problems have their roots within the aggression and victimization that can result from relationship problems with peers and others. Aboriginal children disproportionately experience the high levels of personal and intra. racial violence which are often attributed to bullying and its complex causal pathways (Whaley 1992; Unnever and Cornell 2004; Craven and Bodkin-Andrews 2006; Harris, Lieberman et al. 2007; Beaty, Alexeyev et al. 2008).

Cultural construct (that is, the creation and maintenance of true and accurate cultural representation), plays a major role in research undertaken in an Aboriginal context (Foley 2003). Successful, community driven research agendas within an Aboriginal Australian context have been documented, where the community is free to decide upon the elements of Aboriginal researchsuch as the cultural agenda - without the worry of pre-formulated agendas from mainstream. driven research projects. As Dutta (Dutta 2007) explains, a culture-centered approach is a commitment to theories and applications from within the culture, and is useful in bringing the voices forward and offering alternative entry points to open up discursive voices of those who may be marginalized. This approach further legitimizes the cultural knowledge component of the research context and highlights its importance in any Aboriginal-based research. Further, it recognizes both Aboriginal and non-Aboriginal researchers (McCoy 2008) as being integral components of Aboriginal-based research, with conscious participation in the cultural aspirations, preferences, and practices of the research participants.
The Solid Kids Solid Schools (SKSS) project, on which this paper is based, was developed to better understand bullying within an Aboriginal cultural construct (that is, what it looks like and feels like in an Aboriginal context) (Coffin 2008). Despite the emergence over the last two decades of an impressive body of knowledge on the impact of childhood trauma on emotional health (Dahlberg 1998), this has only recently been extended to an Aboriginal context, where the picture is different and the trauma, in many instances, is far more severe (Zubrick SR, Silburn SR et al. 2005.).

This project was guided by the views and expectations of research conducted within the community of the Aboriginal participants. Aboriginal adults expected that research among their children and families would have leadership from an Aboriginal community member at all times and the engagement of an Aboriginal epistemological positioning around knowledge creation and ownership. This also helped to establish relationships and to maintain cultural construct integrity (Coffin 2008).

The voice of the Aboriginal child on issues around bullying has not been heard. This paper uses Aboriginal children's voices to learn where bullying occurs, and in what contexts, what it looks like, its causes, and its effects. It provides some direction to minimize the impact of bullying on Aboriginal children and youth in school, families and communities.

\section{Methods}

The goal of the SKSS project was to contextualize bullying behavior(s) and translate this knowledge into community owned and identified strategies in the Yamaji region (Midwest /Murchison) of Western Australia. Three locations within the Yamaji region were used within the study. These can be best described as a regional town (population of 35,000 ), a remote inland community/town (population of 800), and small coastal rural town (population of 9,000) (Australian, Bureau et al. 2007-08). 


\section{Sampling}

140 children/youth (aged 8yrs to 18yrs) were interviewed. These children/youth came from schools in all three locations. The regional town has four high schools - Catholic, Public, Grammar and Christian. The state high school has the largest student enrolment and a much higher proportion of Aboriginal students (40\%) than do the other schools. The next largest high school is the Catholic school with only $5 \%$ Aboriginal enrolment at the time of the interviews. In comparison, the state school and the Independent school in the remote town have 93\% and 99\% Aboriginal enrolment respectively. Regional schools have between 300 and 500 students, compared to remote schools where numbers fluctuate dramatically and average around 120 students. The coastal rural town has similar Aboriginal enrolment numbers to the regional town, but has a higher proportion of Aboriginal students located in its lower secondary schooling system. Both the coastal rural and the regional town have around 15\% Aboriginal and Torres Strait Islander enrolment in their upper secondary years (all statistics based on the Midwest Education Department Data, 2008). The results were collected in the space of approximately two years over 2008 and 2009.

The methodology used to review children's issues around bullying involved:

- Working with an Aboriginal steering group

- Developing and piloting the interview guide

- Recruiting/training Aboriginal research assistants

- Conducting interviews with children from the three locations

- Organizing focus groups

- Analyzing results

- Following up findings with schools and communities.

\section{Aboriginal Steering Group}

A critical component of this project was the formation of a regional Aboriginal Steering Group comprised of Aboriginal community leaders. This group provided advice on each stage of the project, from data collection and interpretation through to follow up and dissemination. Additionally, the steering group provided a conduit between the research project and the community, often encouraging people to become involved, and informally updating the community about the project's progress. As issues were raised and a more global perspective was required than that of members of the steering group, each member networked within the community and collected feedback, which was then communicated to the research team. Although there were no young people in the steering group, their opinions were sought throughout the project using talking circles (Power 2004), youth workshops, and small gender-specific focus groups.

\section{Development and Piloting of the Interview Guides}

Creating a safe space for Aboriginal students to verbalise, in their own words, what bullying feels and looks like is fundamental to developing an understanding of the complexity of this issue. An interview guide was developed and validated with the steering group's involvement, and pilot tested by the Aboriginal research assistants with a convenience sample of five students in each age category (8.12 and 13.18 years of age). Some of the questions were adapted from previous research conducted by Trevaskis (Trevaskis 2003).

The interview guide comprised five main parts including an introduction, a background and permission form, and several warm-up familiarity questions, followed by key questions and an additional comments section. The key questions for participants (primary children aged 8.12 years and youth aged 13.18 years) were grouped into questions around family and community connections such as: 
- How many cousins do you have at school?

- Do you mix with them all the time?

- Who lives with you?

- Do many of your siblings go to this school or do any family work here at school?

There were also questions about personal interests and general feelings about school. Discussions were open ended and children/ youth were asked their personal opinions on life in the community, family and community connectedness, school life, home life and also about who is the best person to help them solve issues around relationships and personal issues that may arise. Children/youth were also asked to comment on what was needed and currently may not be available to help solve any of the issues they may have brought up in the interview.

In all interviews, language and the individual's understanding of bullying were clearly defined. Bullying was introduced by asking participants what they liked and disliked about school and community life. If bullying behavior was not raised by a participant unprompted, pictures were utilized as a uniform cue and participants were asked to describe the behaviors depicted. The pictures were used with the majority of primary school aged children but were rarely used with high school or older students. These pictures also reduced interviewer variation and possible language confusion, especially with slang words, such as 'deadly', which means different things to different people. Participants were asked to describe the behaviors depicted. After discussing the picture or bullying behavior described by the participants, interviewers asked a standardized question about the frequency of bullying involving the student and, more generally, in their community.

Interviewers encouraged those they interviewed to describe their physical and emotional responses to bullying behavior. Often the physical response formed the main component of the 'story' or answer to the posed question. This was captured by the interviewer taking notes, for example; "Child $\mathrm{x}$, got up from his seat and acted out how the beating was administered with a full account of the events that had taken place...". The emotional and emotive-type responses and language were further explored with those who had a good rapport with the interviewer and felt safe enough to offer this.

Participants were asked about the frequency of bullying both at school and within broader community life. With the focus on "what do you see" rather than what happens to you personally. The rate refers to what was happening to them and/ or around them in their school setting or within life in the wider community. Frequency questions were asked in such a way that participants could utilize their own language, for example, when talking about rates of bullying behavior. Due to differences in language ability and stage of development, high school youths were not as descriptive as the primary school children. For example, it is hard to determine exactly what the word 'sometimes' means, and at times opposing meanings had been combined, such as 'almost every day/not that much'.

The conclusion to the interview had several open-ended questions where the participants could offer an opinion or ideas towards a solution to the issues they had discussed. For example "What do you think would make school and community life better for you and or other children/youth in this town?".

\section{Recruitment/Training of Aboriginal Research Assistants}

Two female and one male Aboriginal research assistant were trained to conduct interviews, transcribe tapes, and assist in coding the text. The research assistants used their local knowledge and networks within the community to recruit participants, provide information on appropriate language, and maintain cultural security (Coffin 2008).

The interview procedure was consistent with best practice for interviewing children and adolescents, as described by Wilson and Powell, 
including elements such as alternative framing of questions to avoid guilt and feelings of 'dobbing'2 (Wilson, et al. 2001; Wilson and Powell 2001). This questioning technique is particularly important in the area of bullying, as many children do not want to be stigmatised as a 'dobber', and worry it will lead to further victimization. Other best practice principles used in the interviews included:

- The interviewer doing the least talking; and

- Using questions which are open ended, focused on the child's needs, responsive to the responses provided, and which remain adaptable throughout the interview process.

The interviews utilized identification markers as part of normal questioning, and interviewers used the introductory phase of the interviews to build rapport and to explain what the interviewee could expect, with a focus on confidentiality and honesty.

Wherever possible, male researchers interviewed male participants and females interviewed female participants. In an Aboriginal context gender roles are very important and it is more likely that each gender will engage better as a young male would not open up about personal information to an unknown female and vice versa. Gender specific interviewing maintains cultural integrity for Aboriginal participants and researchers involved. Interviews were taped, and transcribed by an Aboriginal transcriber or one of the appropriate Aboriginal researchers. While interviews varied according to an individual's situation, the average duration was 40 minutes. Aboriginal researcher assistants who were

2 'Dobbing", is the same as telling, it is reporting behaviors to usually an older more authorative person. responsible for conducting the interviews throughout the research were also given time after each interview to debrief and conduct a brief analysis of the interviews in relation to what went well and what needed improvement.

\section{Interview Recruitment}

Purposeful area and snowball sampling (Sarantakos 1993) was utilized to recruit participants through the use of the SKSS Steering Group and Aboriginal and Islander Education Officers (AIEO) ${ }^{3}$ based in each of the target schools. This process ensured the sample represented a range of localities and schools, and involved children from Year 4 to Year 7 (8 to 12 years) and Year 8 to Year 10 (13 to 16 years). Additionally, several interviews were held with individuals who had left school (described as 'disengaged' were placed in age appropriate categories in Table 1). These youth were categorized in the appropriate locality and classed as high school age (age appropriate). Consent was obtained from parents/ caregivers and from the children/youth for each interview. This was usually done in person by an AIEO or Aboriginal researcher visiting the child's home or by contacting parents/caregivers in another way, such as at local sports events or school assemblies. Table 1 below describes the location and gender spread of children/youth interviewed.

3 AIEO, or also known as ATA or AEW in other systems other than the state education system

Table 1. Distribution, gender and number of children and youth interviewed in SKSS

\begin{tabular}{|c|c|c|c|c|c|c|c|}
\hline & \multicolumn{2}{|c|}{ Regional town } & \multicolumn{2}{|c|}{ Coastal Town } & \multicolumn{2}{|c|}{ Remote } & \multirow[b]{2}{*}{ Total } \\
\hline & $\begin{array}{c}\text { Primary School } \\
\text { (2 state/1 catholic) }\end{array}$ & $\begin{array}{l}\text { High } \\
\text { School }\end{array}$ & $\begin{array}{l}\text { Primary } \\
\text { School }\end{array}$ & $\begin{array}{l}\text { High } \\
\text { School }\end{array}$ & $\begin{array}{l}\text { District High } \\
\text { School }\end{array}$ & $\begin{array}{l}\text { School } \\
\text { residential } \\
\text { remote }\end{array}$ & \\
\hline Male & 28 & 11 & 9 & 3 & 7 (primary) & 8 & 66 \\
\hline Female & 35 & 2 & 16 & 2 & 9 (primary) & 10 & 74 \\
\hline
\end{tabular}




\section{Focus Groups}

Focus groups were held with:

1. Youth of high school age from Geraldton Residential;

2. Children/youth at Gunnadoo Farm School Holiday program (aged 8 to 17 years); and

3. Geraldton Aboriginal Streetworkers Holiday Program participants (aged 8 to 14 years).

While interviews had been planned, the focus groups were held instead as some members of these three groups asked to be together. Each focus group was gender-specific and lasted no more than an hour and a half. The questions used were similar to those utilized with individual interviews. Groups were no larger than eight and privacy was maintained for these groups during the focus questions.

\section{Analysis}

Colaizzis' (1978) framework was used to conduct the analysis to maximize validity and maintain the 'community voice', ownership and representation (Coffin 2008). Since most interviews were conducted by female Aboriginal researchers, the transcripts of interviews with males were checked by a male Aboriginal researcher to ensure gender equity. To maintain dependability (Bryman 2004), transcripts were read three times, firstly by the author (AR1), secondly by another Aboriginal researcher familiar with the work (AR2), and thirdly, in summary form by the steering committee members.

Summary points and main themes that evolved from these data were then double-checked, and validated, changed, and/or discussed if required. For example, AR1 found a pattern to describe bullying behaviors, and AR2 reviewed the data to validate the pattern and, where appropriate, added further supporting information. At times, AR2 found different themes, which were either added to the list, or used to alter the definitions of existing themes. After presenting the themes to the steering group, each theme was deemed to be either significant or secondary. This process consisted of much discussion and voting. Some significant themes were presented to the steering group and to be validated by the community. The process also determined if there was any pattern or similar examples from the study region to validate these findings; or if they were unique to one school/area in the region. This approach strengthened the information that formed part of a summary document distributed to all schools and communities.

Responses were coded through QSR Nvivo software (QSR, International et al. 2007). The initial coding results were open-ended, however after the steps described above, more selective coding was systematically applied (Glaser and Strauss 1967). A condensed set of data was then analyzed to identify any linkages and to consolidate or dispute earlier or ongoing theory.

\section{Follow-up/Translation to Schools and Communities}

Follow up with communities was an integral part of the research. Information from interviews and focus groups was taken back to representative community groups for validation or further insights.

With the themes endorsed or modified by the steering group, a summary for each region was prepared and sent back to all schools and community groups (including parents, care givers, youth workers) involved with the project and others who could benefit from such localized knowledge. Additional knowledge-translation activities included newspaper publicity, articles in local and state papers, and conference presentations about the findings and possible actions to address the findings.

\section{RESULTS}

The interviews with children/youth provided information about what bullying looks like, feels like, its frequency, where it happens and to whom, and who Yamaji children/youth tell when they are being bullied. The interviews also addressed what 
the participants wanted done about bullying, and some of the complexities around the issue of bullying and its cultural implications for Aboriginal children and youth.

\section{Frequency of Bullying}

Unlike young people of secondary school age, primary school aged children readily quantified their bullying experiences. Nearly $40 \%$ reported that bullying happens at their school every day. A typical response was "Yep, all the time, might as well say every day." Just $16 \%$ of youth reported that bullying happened all the time/every day, while nearly a quarter reported that bullying happens, every couple of days/weekly at their school. However, $43 \%$ gave a relatively non-committal answer, acknowledging that 'it happens', or it happens 'sometimes'. Just over $14 \%$ of younger children used the term 'sometimes', whereas over two thirds of them gave a quantifiable answer.

Some differences were evident by gender, school type and locality. Boys and girls were equally likely to report that bullying happened daily in primary school, but among the youth, females were more likely to report bullying as a daily occurrence. Most male and female students at the two residential schools reported that bullying occurred daily. Interestingly, the proportion of Aboriginal students enrolled within a school did not appear to have a direct influence on the frequency of reported bullying in that school.

\section{The 'Language' of Bullying}

The children in this study described bullying as "Big kids picking on little kids". The phrases 'picked on' or 'picking on' were the most commonly used when describing older or bigger kids bullying younger/smaller kids. Twenty five percent of all student respondents mentioned "teased, hitting" and "carrying yearns" to describe bullying, and described bullying as "people picking on people for fun".
Bullying means picking on little kids, teasing them, hitting them and swearing at them. (Male, 12yrs, rural coastal primary school)

Slight variations were found in the words used to describe bullying and in the meanings attached to these words. The differences found between regional/coastal and remote were possibly due to the way the respondents used their 'own' Aboriginal language and the influence of the schooling system. Students in the remote and coastal areas, for example, tended to use the word 'teasing' instead of 'bullying'. For example, "...teasing, picking on little kids..." was a typical response when seeking a definition of bullying. These children and youth used more descriptive language such as 'swearing', 'smashing' and 'hitting'.

In contrast, over $70 \%$ of children/youth from the regional town used the term 'bullying'. When the illustrations of children fighting were used the majority of respondents throughout the region responded with either the word 'bullying' or 'bully'. Children and youth often provided detailed and graphic descriptions of violent bullying behavior, frequently using adult words and concepts of fighting. These children/youth gladly demonstrated some of the more physical forms of bullying they had seen.

The language used by children and youth to describe bullying behaviors was also localized in some instances. Numerous phrases such as "What's your go" were localized and well understood by children as young as 8 years old. This phrase typically means 'let's go and fight' and is a direct challenge from the person who says it to another. Interestingly, no major gender differences were found in terms of the use of language to describe bullying, except that girls generally provided more detailed accounts of physical, social and emotional bullying or to forms of bullying other than the physical kind. 


\section{Feelings Associated with Bullying}

When asked 'How does bullying make you feel?' more than $50 \%$ of all respondents said "sad and angry", with the vast majority of remote respondents indicating that the major cause of unhappiness at school was bullying and teasing.

"I feel so sad, worried and, angry that I punch walls to get it out of my system and then stay away for a while." (Male, 11 yrs, regional primary school)

Again, children provided more detailed descriptions of their feelings than did the youth. However, even the older age group indicated the level of frustration they felt when bullied, saying, for example, "you get hit and then you either take this anger out on someone smaller or weaker than you...". Some students talked about 'payback' and being prepared to 'wait until the person bullying was older when they would be an easier target' or spoke of how they would redirect their aggression onto weaker siblings, family and others.

While many children and youth felt that school was 'good' because they had lots of friends, some mentioned that when they had only a few friends or were new, school was not a place of happiness.

The most prominent observation relating to feelings about bullying was the lack of emotion shown by Aboriginal children when describing harrowing bullying experiences. Their responses seemed to indicate they were everyday 'normal' and accepted behaviors and just part of life. In contrast, a few children/youth used strongly emotive words such as 'terrorized', and were clearly distressed and anxious about the bullying and violence they had witnessed or experienced. They described the behaviors as 'unacceptable and unfair', 'not normal', and something they wanted 'corrected almost immediately'.

When I was in Year 8 it used to happen a lot, I think the other kids thought that it was funny but they didn't know how that hurt my feelings. (Female 15 yrs, disengaged, coastal rural)
Interestingly a few children indicated they felt a bit sorry or sad for the victims of bullying, although this response was rare.

Um, they bully different colored skin kids, um like last year at the school we had this one girl and she was a bit muminge (simple) and people kept on teasing her and hitting her and all that so she left and that's sad. (Female 14 yrs, remote)

\section{What Bullying Looks Like}

The size of the perpetrator and of the person being victimized was a major descriptor when talking about bullying with all respondents. Over half of all students referred to the 'big' students verbally or physically picking on the 'little' students. The theme of bigger-bullying-smaller was consistent throughout the whole region.

The majority of respondents, when describing what bullying is or looks like mentioned it was 'Aboriginal kids bullying Aboriginal kids'. Aboriginal children and youth also indicated that while bullying was also perpetrated by non-Aboriginal students they felt it was not as frequent as intraracial bullying and that it didn't hurt as much.

Children suggested that 'bullying', or 'running somebody down' seemed to be normalized behavior. They said it was just "something that Aboriginal people do", intrinsically linked to being a 'proper' Aboriginal.

When children arrive from different Aboriginal language groups ${ }^{4}$, this can be extremely confronting. Aboriginal children often report feeling threatened or fearful when entering another community/school, partly due to the lack of family support as well as how other language groups not from that local area might be treated. Being from another area and feeling uncomfortable that they might be bullied was mentioned by more males than females in this study, and only among the youth.

4 Different regions have many diverse language and or tribal groupings, long standing confrontation is sometimes present and preconceived ideas about groups are formed through generations and handed down to children/youth. 


\section{Why Bullying Occurs}

Aboriginal youths consistently responded that the major causes of bullying were boredom (30\%), jealousy (60\%), and drugs and alcohol (95\%). For the majority of children (95\%) boredom was also a prominent reporting followed by just 'wanting to be the boss' and that the perpetrators 'just can't help it' as major causes of bullying. Children also mentioned drugs and alcohol as a common factor related to why some people bully others. A small number of male children indicated that some people bullied others to gain attention and friends.

A feeling of jealousy towards other Aboriginal students was also mentioned as an issue that contributes to intra-racial divisions and bullying, especially in the wider community. Personal or physical features and sexuality (sexual jealousy) also ranked highly among the reasons why young people in this study were bullied, especially in the remote region. There was no mention of positive image and/or of positive associations and being proud to be Aboriginal by any of the children interviewed. Questions were geared toward students being able to provide a positive and or negative response, for example "What do you like about living in this community? And what don't you like so much about living in this community?"

Ifeel alright today. Lastweek, well yesterday, I cried because um, these, um this one boy was bullying me. I told the teacher but I'm getting sick of people calling me names, yeah, such as Big Bird and swearing at me and that. They are in the same year as me and they are boys and girls. (Female, 11 yrs, coastal)

The normalization of this behavior was evident in comments from both children and youth, suggesting there was legitimate place for older cousins, siblings or family members to bully others and 'sort out' an issue. This perception is likely to maintain a bullying cycle, with children and youth talking about 'payback', or 'getting their payback', particularly among the female youth living in coastal and remote towns. Children and youth reported that they feel compelled to fight and be strong for their family. In the Aboriginal context, this includes cousins, distant relatives and lifetime friends (that is not exclusively family). Young people reported a great sense of family pride and loyalty and the following two quotes exemplify this:

I don't like it when we fighting, swearing, ... the other girls fight with my sisters and then I gotta fight. (Female, 14yrs, remote)

\section{Where Bullying Occurs}

Children of all ages, locations, and school types reported that their school was where bullying is most likely to occur. Children from the entire region described how easy it was for bullying to occur and that teachers did not take action to stop it.

... only place kids can catch one another. At school there is a crowd. (Male, 12 yrs, regional town)

Mainly playground, oval, undercover area, when the teacher leaves the class - even for a second, the other kids start teasing and calling names and when we tell the teacher they don't do nothing. (Male, 9 yrs, remote)

Sport was also mentioned frequently as an opportunity for bullying or family fighting and dominance.

Teasing all the time, where no teacher when we playing or in sports time it happens. (Male, 12 yrs, remote)

Children and youth, especially girls, felt that there was nowhere to go for help if they were bullied after school hours, while the youth indicated that when you are being bullied "no place is really safe except in your own house".

\section{Who do Students Tell about Bullying?}

Yep, nearly every day but once really bad um, I told the Teacher and they sorted it out. (Male, 12yrs, remote) 
Yamaji children reported that when bullying occurred, they mostly tell their teacher (52\%), and their mother (20\%). In contrast, youths are more likely to tell their mother first $(40 \%)$, then their teacher, Nana, and relatives (12\%). Interestingly the children reported a longer list of people from whom they could seek help than did the youths.

In remote and coastal towns, most children who reported the bullying told their teacher or the school principal, and their main care giver, nana or mum, whereas the youth from the coastal area were more likely to report the bullying to their family, predominately their Mother. A small number of these coastal area youth indicated that they would only tell their family and not the school staff, as they felt the staff weren't helpful, and it would be a 'waste of time'.

In contrast, youth in the regional town were more likely to tell their mother, AIEO, friends, and other accessible adults such as school counselors, chaplains, mentors and youth workers.

Very few of the youth mentioned they would talk to a male family member, such that dad, uncle, and pop were only mentioned once. This could be due to a lack of responsible males in the young person's family unit, or to the mother being more pivotal in the child's life. Some children and youth reported that they largely had no-one with whom they could talk if they were bullied.

Um ...I don't know, sometimes I tell the teachers but the kids keep on doing it so, um no one really ... (Male, 11yrs, coastal)

\section{I am a Person Who Bullies...}

Approximately $15 \%$ of children and youth openly admitted to being a 'bully' 'sometimes' or 'all the time/everyday' or indicated they had previously bullied others.

... every day, every couple of days, depends on how I am feeling. (Female, 12 yrs, coastal town)

All the time. Anytime. Whenever I feel like it. (Female, 12yrs, regional town)
Even though more students from the remote residential school reported being bullied, fewer remote students admitted they bullied others compared to students from the coastal town, but some indicated they would bully back if they were bullied. Slightly more males admitted to bullying others than females, although bullying others was reported most frequently among boys from year 5 to 7, with the majority of overall bullying reported among boys and girls in Year 7.

\section{The Importance of Friends}

Friends rate highly as a protective factor against bullying for Yamaji children/youth. There were more than twice as many positive comments related to having friends as there were negative comments around friends (56 compared to 19). Students, especially primary school aged males, mentioned bullying as a means to gain attention and friends, but interestingly three young males mentioned that their peers talked about having been 'taught to bully' to gain friends.

There was also a direct positive correlation between friends at school and having multiple siblings/cousins at school.

Oh well like we fight about whose friend, like we have to pick like best friends and stuff. But I don't reckon we should because that hurts other people's feelings. And some people get left out like we always often get left out all the time. It's mainly me and $S$ who get left out. (Female, 12 yrs regional town)

Children from other areas felt this isolation and some felt culturally as well as socially isolated for large periods of time - for example 'all last year, after when I first came here'.

\section{What do Children/Youth Want Done about Bullying}

Almost all students reported they wanted the issue to be resolved, although many indicated they often had to resolve it alone, because telling an adult was interpreted as weak. Many children 
and youth suffer in silence. Some children and youth acknowledged they were not sure what teachers could do about bullying, yet they still wanted teachers to 'fix it'.

Um I don't know (ha ha) probably take the kids aside and talk to them and work out a solution like separate the class or something ... (Male, 14yrs, regional)

Some suggestions from children and youth for teacher responses included telling them to stop and verbally chastising them, while children wanted the people bullying to apologize - "make them apologize to me."

Finally, some suggested parents should be part of the solution and that they should give their child 'a hiding' 5 if they bullied others. However, more commonly children/youth felt positive that parents respond to bullying by keeping kids home from school until the issue settles down. Many children/youth felt it was 'normal' to stay home when socially or emotionally challenged.

I want them to tell her off and tell her to stop. (Male, 12yrs, remote)

Just tell the parents of the other kids and tell them to make them stop it and make them get a hiding. (Female, 11yrs, remote)

\section{Discussion}

This paper explores concepts held by Aboriginal children and youth about bullying. The culturally, linguistically and geographically specific study conducted provides an in-depth analysis of Aboriginal children's and youths' experiences of bullying behavior. The respondents very rarely referred to ethnicity in the interview, although when it was 'whitefella' specific, this was spelled out by the students. Hence, given an Aboriginal interviewer conducted all interviews, it appears the Aboriginal children and youth were discussing intra-racial bullying or bullying involving other

5 Physically hurt them
Aboriginal children that often involved their own family and other Aboriginal families.

The two most important and unique contributions of this study are:

- How Aboriginal children and youths' identity and cultural obligation impact on the likelihood of them being involved in bullying behavior; and

- Consequently, the largely intra-racial nature of the bullying described by the participants.

\section{Aboriginality and Identity}

The normative expectations and social norms to act or respond demonstrating one's Aboriginality, especially from pre-adolescence and onwards, appears to increase children's and youths' vulnerability to being victimized and/or to perpetrate bullying behavior (Kickett-Tucker and Coffin 2010).

Aboriginal children and youth reported they often didn't have a choice in how they respond to potentially threatening situations, because of their intrinsic need to adhere to their Aboriginality. This was particularly evident when their identity was under threat, such as a racial slur or when they experienced tribal or language group alienation. Children and youth needed modeling of positive responses, so that a taunt such as 'oh you people just live in the bush' could be met with a positive response about their survival and hunting skills and their great utilization of resources in the environment.

Similarly, Aboriginal children and youth described feeling threatened intra-racially when entering another community and/or school if they didn't have cultural support (such as language recognition of other groups, other people of their cultural group, people who understand Aboriginal culture and have knowledge about Aboriginal ways etc). Interestingly more males than females in the older age group (12 years upwards) felt more exposed to bullying victimization due to threats about their identity. 
A major factor that Aboriginal children and youth said caused intra-racial bullying was jealousy. Perceived inequity among respondents such as owning better clothing or receiving sporting or scholarly accolades was a factor that led to jealousy, which was often expressed through aggression and bullying. This may occur because among Aboriginal people resources were traditionally shared equally within the community, whereas today many Aboriginal communities no longer function in this way because of influx of money and housing and stigmatization (Foley 2003).

Bullying, or running somebody down was also deemed by respondents to be normalized behavior and was just 'something that Aboriginal people do', intrinsically linked to being a 'proper' Aboriginal. Although there were no specific questions about positive image, there was no mention of a positive image and/or positive associations and being proud to be Aboriginal by any children or youth who were interviewed. This absence of positive associations and pride in being Aboriginal was striking.

Being bullied (mostly) verbally in response to jealousy (Bessarab 2006) about one's personal characteristics and/or sexuality was of concern to Aboriginal children and youth, particularly those from remote regions. Female perpetrators were more likely to use nasty language suggesting high levels of promiscuity and unattractiveness, whereas the males tended to bully using terminology that inferred failure, with words like 'loser'.

To respond to this entrenched internalized racism and to counteract this bullying, it is essential that Aboriginal children and youth receive support to build a strong, positive racial identity rather than only focusing on self-esteem related issues (Dudgeon, Garvey et al. 2000; KickettTucker and Coffin 2010). Positive racial identity must include all racial groups taking pride in their contribution to society and accepting differences as a strength - not a reason for division.

\section{Cultural Obligation: How Does This Impact on Children?}

Aboriginal children and youth feel compelled to fight and to be strong for their family, including cousins, distant relatives, lifetime friends and their immediate family. The respondents reported a great sense of family pride and family loyalty. Long standing feuding is sometimes present and preconceived ideas about groups from different Aboriginal language or tribal areas have been formed through generations and handed down to children/youth. The family obligation for children and youth requires them to side with their family or be outside their cultural and family circle. This cultural obligation to behave in accordance with their family can be extremely confronting for Aboriginal children and youth when they first enter a geographically or linguistically different group.

Well ever since l've been here l've felt a little bit nervous. I don't know how to, how I feel and felt real scared because well I just got here and I don't know most of the kids at school their names but they all know my name. And because I don't know them and I want to be all the kids friends, but I don't know their names and they just look at me and what I look like or what I do. Like if they look after me I said to myself, I'll look after them. And now I get bullied all the time because I look after my own, I'll kill for my family and friends. And back in $X$ whether it's my brother or sister or friend and they get hurt I just always want to get to help them out and to protect them from people that try to hurt them. (Male, $7 \mathrm{yrs}$, regional town)

Having friends and or family within the school setting was described as a double edged sword. With friends, and sometimes with family (e.g. having multiple siblings/cousins at school), respondents described security and popularity. However, friends also came with the obligation to 'stick up' for them or be on the outer of the friendship circle. Some children and youth 
reported being outside of friendship circles as a result of family feuding within the community. Feuding is a damaging issue for children/youth and adults alike within the community. It is often subtle and long standing, it can be physical in nature but for children and youth, it is more often about exclusion and intimidation.

\section{What Does This Mean?}

One of the unique findings in this study is the extent to which bullying in the communities studied was intra-racial. Intra-racial bullying was pervasive, and damaging. Intra-racial bullying attacks the core of Aboriginal children's and youths' being, their Aboriginality (Kickett-Tucker 2008). This factor alone could represent one of the most important areas in need of intervention in order to support both Aboriginal children and youth. Aboriginal children and youth need to be given opportunities to describe how they are feeling about these complex relationship issues and what can be done to address them.

There exists an overburden of relationship issues for families and parents, with cyclic events such as poverty, unemployment, goal terms, drugs and alcohol abuse, overcrowding, hopelessness), as well as wider racial, societal and discriminatory issues. The burden of these relationship issues and complex social issues ultimately comes to rest with the children/youth and their caregivers. By contextualizing what bullying looks and feels like for Aboriginal children and youth, we can determine more clearly the most culturally secure ways to address this problem. Children and youth need to be able to build relationships with a neutral person who has the cultural understanding of their individual situation but also who has the ability and power to go respectfully into the community and help create practical solutions. Sustainability of any project or research outcomes are achieved from partnership with, and engagement of, Aboriginal communities within the region, and the establishment of 'public' displays within school grounds to demonstrate these partnerships, (e.g. language welcome, art works, visiting speakers, plaques). Displays showing famous Aboriginal people from the region and positive contributions of Aboriginal people from the region would also assist in engendering pride and positive attitudes amongst Aboriginal children and youth. It involves the community truly becoming part of the process of change, not just being invited in as an afterthought without any real power to change or develop direction (Chandler and Lalonde 2004).

Aboriginal children and youth are frustrated. In primary school Aboriginal children tell the teacher about bullying, often with limited results. Similarly Aboriginal youth report they don't tell teachers, possibly because they are not able build relationships with teachers like primary aged students, or possibly because they have learnt in their younger years that typically nothing happens if they do tell.

What is clear is that the respondents don't want bullying behavior to continue, they want consequences and someone in authority to take action (Varjas, Meyers et al. 2008). The Aboriginal Indigenous Education Officer (AIEO) was barely mentioned as a person who could provide help with bullying, unless they were also a family member. It appears, in some contexts, that the AIEOs have a type of 'invisibility' in relation to social and relationship issues (Partington and Galloway 2007). By not actively engaging AlEOs to help deal with bullying issues, the education system may be missing a vital culturally secure intervention opportunity. To address this situation, the status of the Aboriginal Indigenous Education Officer role should be raised within the system and incumbents given more training in how to more effectively respond to the very complex social and emotional health issues experienced by, and between, Aboriginal students.

Having a high Aboriginal student enrolment does not appear to be a solution to protect Aboriginal children and youth from bullying. Strategies that do appear to be protective against bullying, however, are: 
- Having high numbers of visible and well trained Aboriginal staff in schools who are accessible to students;

- Having the positive contributions of Aboriginal people to society and the wider social positives of being Aboriginal reflected in schools and school grounds; and

- Providing a safe common room or shared space for Aboriginal students in schools, (students reported this as a helpful factor in solving bullying issues).

\section{Conclusion}

The research has only begun to document the experiences of Aboriginal children/youth and their experiences with bullying. Two of the most interesting and surprising results of the research were the extent to which the bullying experienced or observed by the participants was intra-racial and that this hurt more than inter-racial bullying, and the notable lack of positive comments by the participants about their Aboriginality. The research also showed that Aboriginal children and youth want parents and teachers to deal with bullying, but they are often ineffectual in their efforts to deal with it. To date, we have not given our teachers and/or parents adequate tools to effectively deal with bullying related issues, especially intra-racial bullying, to the scale and degree that is required.

It appears that schools and communities mostly take notice of physical bullying and aggression, probably due to safety reasons and duty of care and because it is more obvious. It also seems that attention to this issue often comes too late when the problem has become too large to be dealt with easily and is confounded by other community issues such as family feuding. Internalized racism and feuding among families and wider groups affect the most vulnerable among the Aboriginal population. To address these complex social and societal issues it is essential to rebuild positive/ strong Aboriginal identity within all Aboriginal communities (Kickett-Tucker and Coffin 2010).

\section{Summary of what will make the most difference:}

- More resources, capacity and skillsbased training for schools, teachers, parents and AIEO's with training to help them address the mental, emotional health needs of Aboriginal students.

- Provision of more school-based psychologists with training in culturally secure practice to support Aboriginal students and families

- Adoption of locally developed and informed practical resources and training (linked to community needs) addressing both prevention and management of bullying and relationship issues provided to parents and teachers such as www. solidkids.com.au.

- Engagement of, and a true partnership with, the community showing positive associations with Aboriginal people from the region.

\section{References}

Australian, Bureau, et al. (2007-08). Regional Population Growth - Australia, ABS.

Beaty, L. A., E. B. Alexeyev, et al. (2008). The Problem of school Bullies: What the research tells us. Adolescence, 43(169): 1-11.

Bessarab, D. (2006). A Study into the Meanings of Gender by Aboriginal People Living in Urban(Perth) and Regional (Broome) Settings. (Unpublished) Doctor of Philosophy Thesis. Faculty of Education, Language Studies and Social Work (ELSSW) Department of Social Work \&Social Policy, Curtin University of Technology, .

Bishop, R. (1998). Freeing ourselves from a neo-colonial domination in research : a Maori approach to creating knowledge. Qualitative Studies In Eduation, 11(2): 199-219. 
Boon, H. J. (2008) Students at risk: a bioecological investigation. VDM Verlag Dr.MüllerAktiengesellschaft \& Co. KG: Saarbruecken, Germany. ISBN: 978 3836486458.

Bryman, A. (2004). Social Research Methods. UK., Oxford University Press.

Chandler, M. and C. Lalonde (2004). Transferring whose knowledge? Exchanging whose best Practices? Toronto, Thompson Educational Publishing.

Coffin, J. (2008). Embedding Cultural Security in Bullying Prevention Research. Manifestation: Journal of Community Engaged Research and Learning Partnerships, 1(1).

Colaizzi , P. F. (1978). Psychological research as the phenomenologist sees it. In R.Valle \& M. (Eds.) King, Existential phenomenological alternatives for psychology. New York: Oxford University Press.

Craven, R. and G. Bodkin-Andrews (2006), New Solutions for Addressing Indigenous Mental Health; A Call to Counsellors to Introduce the New Positive Psychology of Success. Australian Journal of Guidance and Counselling, 16(1): 41-54.

Dahlberg, L. L. (1998). Youth violence in the United States: Major trends, risk factors and prevention approaches. American Journal of Preventive Medicine, 14(4): 259-272.

Dudgeon, P., D. Garvey, et al. (2000). Working with Indigenous Australians: A Handbook for Psychologists. Perth, Gunada Press.

Dutta, M. (2007). Communicating About Culture and Health: Theorizing Culture-Centred and Cultural Sensitivity Approaches. International Communication Association, 17: 304-328.

Foley, D. (2003). An Exammination of Indigenous Australian entrepeneurs. Journal Of development and Entrepreneurship, 8(2):133-151. Accessed from http://www.oeeo.wa.gov.au/documents/ diversitybizz/past\%20articles/An\%20examination\%20 of\%20Indigenous\%20Australian\%20entrepreneurs.pdf.

Foley, D. (2003). Social Alternatives. Indigenous Epistemology and Indigenous Standpoint Theory, 22(1).

Glaser, B. and A. Strauss (1967). The Discovery of Grounded Theory: Strategies for Qualitative Research. Chicago, Aldine Publishing Company.

Griffin Smith, R. and A. M. Gross (2006). Bullying; Prevalence and the Effect of Age and Gender. Child and Behaviour Therapy, 28(4): 13-37.
Harris, W., A. Lieberman, et al. (2007). In The Best Interests of Society. Journal of Child Psychology and Psychiatry, 4(48): 392.411.

Kickett-Tucker, C. (2008). How Aboriginal Peer Interactions in Upper Primary School Sport Support Aboriginal Identity. The Australian Journal of Indigenous Education, 37.

Kickett-Tucker, C. and J. Coffin (2010). Aboriginal selfconcept and racial identity: practical solutions for teachers. ACER Press Camberwell, Victoria.

Kids Help Line. (2005). Callers From Indigenous Backgrounds. 2008, from http://www.kidshelp. com.au/upload/14500.pdf.

McCoy, B. (2008). Holding Men: Kanyirninpa and the health of Aboriginal men. Canberra, AIATSIS, Aboriginal Studies Press.

Olweus, D. (1997). Bully/victim problems in school: Knowledge base and an effective intervention program. The Irish Journal of Psychology, 18(2): 170-190.

Partington, G. and A. Galloway (2007). Issues and Poilicies In School Education. In G.Leitner and G. Malcolm (Eds.), The habitat of Australia's aboriginal languages: past, present and future (pp. 236-266). Mouton de Gruyter.

Power, K. (2004). Yarning: A responsive research methodology. Journal Of Australaian Research in Early Childhood Education, 11(1).

QSR, International, et al. (2007). QSR Nvivo. from http://www.qsrinternational.com.

Rigby , K. (1997). "Attitudes an beliefs about bullying among Australian school children." The Irish Journal of Psychology 18(2): 202-220.

Salmivalli, C., A. Kaukiainen, et al. (2005). Anti-bullying intervention: Implementation and outcome. British Journal of Educational Psychology, 75: 465-487.

Sarantakos, S. (1993). Social Research. South Yarra, Macmillan Education Series.

Trevaskis, G. (2003). The Friendly Schools Bullying Intervention Project: Adapting resources for use in remote Indigenous school settings. School of Public Health. Perth, Curtin University of Technology: 125.

Unnever, J. and D. Cornell (2004). Middle Scool Victims of Bullying: Who Reports Being Bullied? Aggressive Behavior, 30: 373-388. 


\section{What Aboriginal Children and Youth in Australia are Saying About Bullying}

Varjas, K., J. Meyers, et al. (2008). Missing Vioces: Fourth through Eighth Grade Urban Students' Perceptions of Bullying. Journal Of School Violence, 7(4).

Whaley, A. L. (1992). A Culturally Sensitive Approach to the Prevention of Interpersonal Violence Among Urban Black Youth. Journal of the National Medical Association, 84(7): 585-588.

Wilson, J. C. and M. B. Powell (Eds.) (2001). A guide to interviewing children: Essential skills for counsellors, police, lawyers and social workers. Allen \& Unwin/ Routledge, crows nest, NSW, Australia/London.

Zubrick SR, Silburn SR, et al. (2005.). The Western Australian Aboriginal Child Health Survey: The Social and Emotional Wellbeing of Aboriginal Children and Young People. The Western Australian Aboriginal Child Health Survey. Perth, Curtin University of Technology and Telethon Institute for Child Health Research,.

Zubrick, S. R., S. R. Silburn, et al. (2005). The Western Australian Aboriginal Child Health Survey: The Social and Emotional Wellbeing of Aboriginal Children and Young People. Perth: Curtin University of Technology and Telethon Institute for Child Health Research. 